\title{
Speed Control of Dual Induction Motor using Fuzzy Controller
}

\author{
Hephzibah Jose Queen.J ${ }^{1}$, Jenifer Rosney.J ${ }^{2}$ \\ ${ }^{I}$ (Assistant Professor/EEE, Maharaja Institute of Technology/Anna University, India) \\ ${ }^{2}$ (EEE, Maharaja Institute of Technology/Anna University, India)
}

\begin{abstract}
This paper demonstrates the speed control of dual induction motor using fuzzy logic controller under unbalanced load conditions. The process for finding weighed vector value for controlling the dual induction motor is presented. The modeling of dual induction motor is also described. The simulation is done in the MATLAB platform to study the effectiveness of the weighed vector control. The study reveals that the fuzzy controller improves the weighed vector speed control of dual induction motor.
\end{abstract}

Keywords: Dual Induction Motor, Fuzzy logic controller, P I (Proportional Integral) Controller, Summation torque and Weighed Vector control.

\section{INTRODUCTION}

Implementation of coordination control of multiple induction motor is very important in industrial applications and transportation systems. There are two categories in coordination control of multiple induction motor. They are

1) Single inverter driving multiple induction motors.

2) Multiple inverter driving multiple induction motors.

The later control is complex because of the increase in number of IGBTs. The single inverter driving multiple induction motor find more advantages because of low cost, light weight, compact structure and less IGBTs. The single inverter drive system can be further divided as follows

1) Multiple-leg inverter control.

2) Vector control.

Multiple leg inverter control found to have its own disadvantages because of increased in use of IGBTs. In vector control of multiple induction motor, some strategies were proposed to control multiple motor fed by the single inverter [1].

This work demonstrates the vector control of dual induction motor using fuzzy logic concept. The weighed vector is obtained using summation torque and stator current of dual induction motor. This weighed vector is used to control the speed of the dual induction motor using fuzzy logic controller. The reason behind the selection of fuzzy logic controller over other controller is because of high accuracy and easy computation [2].

This paper demonstrates the step by step procedure to find the weighted vector which helps to control speed of dual induction motor underbalanced condition. In this work the control is achieved by fuzzy logic controller whose inputs are summation torque and stator current. The simulation is done in MATAB Platform.

This paper comprises of the following sections: Section 2 deals with the block diagram of the proposed system.Section 3 describes in detail about weighed vector control and the weighed vector value calculation.Section 4 comprises of the Simulation of speed control of dual induction motor using fuzzy logic controller in MATLAB platform. The results include the reference current for the twin induction motor, the stator current and electromagnetic torque. Conclusion and future scope is presented in Section 5.

\section{Block Diagram Of The Proposed System}

The figure 1 shows the block diagram of the proposed system which implements fuzzy controller for the speed of dual induction motor. The proposed system involves in the speed control of single inverter dual fed induction motor using fuzzy logic controller [2]. The weighed values are calculated by the fuzzy controllers using the summation torque and stator current of the motors so that the weighed value controls the speed of the induction motor under unbalanced load conditions 


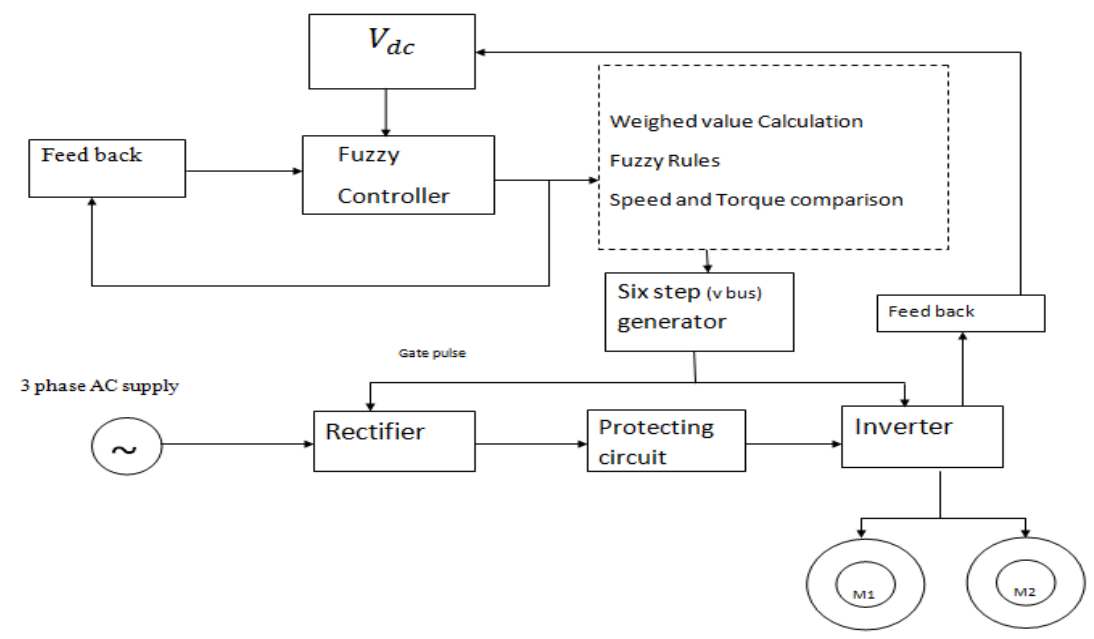

Fig 1: Block diagram of proposed System.

The independent operation of the motors depends on the controlled current input from the controller, thus under unbalanced load conditions the weighed value is calculated and the feedback is given to the controller for better operation.

\section{Weighed Vector CONTROL MOdEl OF DUAL IM'S Fed By The Single Inverter}

The dual induction motors fed by the single inverter has same frequency voltage. The various slip between the two induction motors is caused due to unbalanced load, which results in different speed and stator current of the two induction motors. Generally, the equal vector management is applied to calculate the given excitation current and force current within the existing method [4]. The weighted value $\mathrm{k}_{\mathrm{m}}$ is defined to process the vector control strategy. The figure 2 illustrates the rotor flux and the stator current in $\mathrm{d}-\mathrm{q}$ axis.

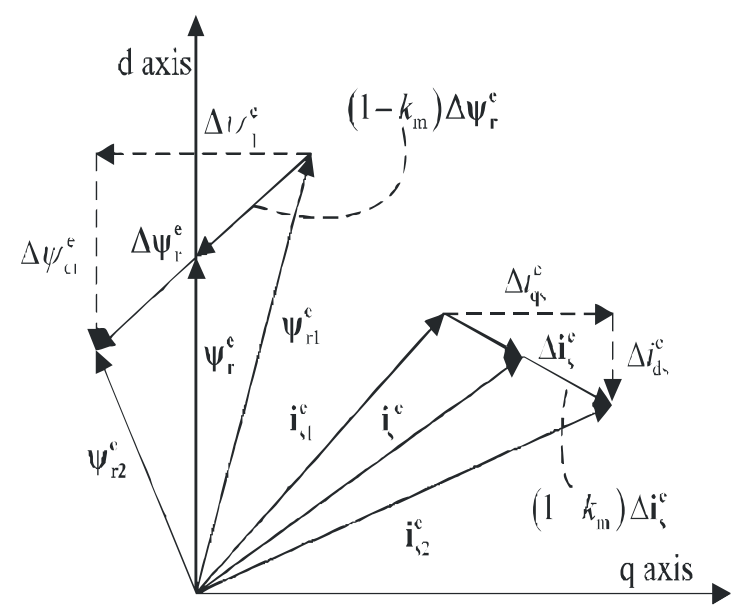

Fig 2: Weighted vector model of dual IMs fed by the single inverter.

The symbols used in section 3 are given in Table 1

Table 1: Symbols used in this section

\begin{tabular}{|c|c|}
\hline \multicolumn{1}{|c|}{ Symbols } & Description \\
\hline $\mathrm{i}_{\mathrm{r}}$ & Rotor current \\
\hline $\mathrm{i}_{\mathrm{a}}$ & Stator current \\
\hline$\Psi_{\mathrm{r}}$ & Rotor flux \\
\hline
\end{tabular}




\begin{tabular}{|c|l|}
\hline$\Psi_{s}$ & Stator flux \\
\hline $\mathrm{l}_{\mathrm{m}}$ & Excitation inductance \\
\hline $\mathrm{l}_{\mathrm{r}}$ & Rotor inductance \\
\hline $\mathrm{d}_{\mathrm{n}}$ & Critical slip \\
\hline $\mathrm{d}_{\mathrm{x}}$ & Increment of critical slip \\
\hline $\mathrm{d}_{\mathrm{p}}$ & decrement of critical slip \\
\hline
\end{tabular}

The rotor flux linkage, stator current, and angular velocity necessary for finding the weighed vector are shown in the equations (1), (2) and (3).

\subsection{Calculation of stator current [4]}

$$
\begin{aligned}
& \Psi_{r}^{e}=k_{m} \Psi_{r 1}^{e}+\left(1-k_{m}\right) \Psi_{r 2}^{e} \\
& \Delta \Psi_{r}^{e}=\Psi_{r 2}^{e}-\Psi_{r 1}^{e} \\
& i_{s}^{e}=k_{m} i_{s 1}^{e}+\left(1-k_{m}\right) i_{s 2}^{e} \\
& \Delta i_{s}^{e}=i_{s 2}^{e}-i_{s 1}^{e} \\
& w_{r}^{e}=k_{m} w_{r 1}+\left(1-k_{m}\right) w_{r 2} \\
& \Delta w_{r}=w_{r 2}-w_{r 1}
\end{aligned}
$$

The equation (4) represents the flux linkage and stator current in $\mathrm{d}$ and $\mathrm{q}$ axis.

$$
\begin{aligned}
& \Psi_{\mathbf{r}}^{e}=\Psi_{d r}^{e} \\
& \Delta \Psi_{r}^{e}=\Delta \Psi_{d r}^{e}+j \Delta \Psi_{q \mathbf{r}}^{e} \\
& i_{s}^{e}=i_{d s}^{e}+j i_{q s}^{e} \\
& \Delta i_{s}^{e}=\Delta i_{d s}^{e}+j \Delta i_{q s}^{e}
\end{aligned}
$$

The rotor flux oriented state equations of the induction motors are given in equation (5). On Substituting equations (1), (2) and( 3 ) in equation (5) we obtain equation (6)

$$
\begin{aligned}
& \frac{d \Psi_{r 1}^{e}}{d t}+\left(s_{r}+j\left(w_{e}-w_{r 1}\right)\right) \Psi_{r 1}^{e}=L_{m} S_{r} i_{s 1}^{e} \\
& \frac{d \Psi_{r 1}^{s}}{d t}+\left(s_{r}+j\left(w_{e}-w_{r 2}\right)\right) \Psi_{r 2}^{e}=L_{m} S_{r} i_{s 1}^{e}
\end{aligned}
$$


$\frac{\mathrm{d}\left(2 \psi_{\mathrm{r}}^{\mathrm{e}}+\mathrm{k}_{\mathrm{w}} \Delta \psi_{\mathrm{r}}^{\mathrm{e}}\right.}{\mathrm{dt}}=$

$$
\begin{aligned}
& =\mathbf{S}_{\mathbf{r}} \mathbf{L}_{\mathrm{m}}\left(2 \mathrm{i}_{\mathrm{s}}^{\mathrm{e}}+\mathbf{k}_{\mathrm{w}} \Delta \mathbf{i}_{\mathrm{s}}^{\mathrm{e}}\right)-\mathrm{S}_{\mathbf{r}}\left(2 \Psi_{\mathrm{r}}^{\mathrm{e}}+\mathbf{k}_{\mathrm{w}} \Delta \Psi_{\mathrm{r}}^{\mathrm{e}}\right)+\mathbf{j}\left(\mathbf{k}_{\mathrm{w}} \Delta \mathbf{w}_{\mathbf{r}} \Psi_{\mathbf{r}}^{\mathrm{e}}+\mathbf{k}_{\mathrm{u}} \Delta \mathbf{w}_{\mathbf{r}} \Delta \Psi_{\mathbf{r}}^{\mathrm{e}}\right. \\
& \left.-\left(\mathbf{w}_{\mathbf{e}}-\mathbf{w}_{\mathbf{r}}\right)\left(2 \Psi_{\mathbf{r}}^{\mathrm{e}}+\mathbf{k}_{\mathbf{w}} \Delta \Psi_{\mathbf{r}}^{\mathrm{e}}\right)\right)
\end{aligned}
$$

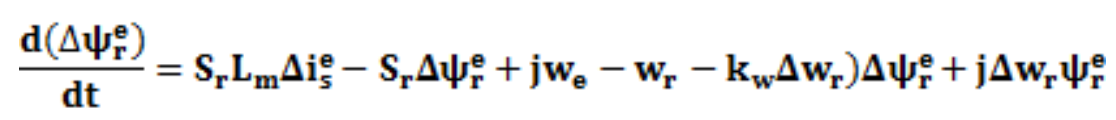

$k_{\mathrm{w}}=2 \mathrm{k}_{\mathrm{m}}^{2}-2 \mathrm{k}_{\mathrm{m}}+1$

$\mathbf{k}_{\mathrm{u}}=2 \mathbf{k}_{\mathrm{m}}-\mathbf{1}$

Now substitute equation (4) in equation (6) in order to represent it in d-q reference. The rotor flux linkage $\Psi_{\mathrm{dr}}^{\mathrm{e}}$ is constant in the $d$ axis, so the deferential of this component is zero $\left(\frac{d \psi d r}{d t}\right)=0$. The resulted equations are

$\mathbf{k}_{\mathrm{w}} \frac{\mathrm{d} \Delta \Psi_{\mathrm{dr}}^{\mathrm{e}}}{\mathrm{dt}}=\mathrm{L}_{\mathrm{m}} \mathrm{S}_{\mathbf{r}}\left(2 \mathrm{i}_{\mathrm{ds}}^{\mathrm{e}}+\mathbf{k}_{\mathrm{w}} \Delta \mathrm{i}_{\mathrm{ds}}^{\mathrm{e}}\right)-\mathrm{S}_{\mathbf{r}}\left(2 \Psi_{\mathrm{dr}}^{\mathrm{e}}+\mathbf{k}_{\mathrm{w}} \Delta \Psi_{\mathrm{dr}}^{\mathrm{e}}\right)+\left(\left(\mathbf{w}_{\mathrm{e}}-\mathbf{w}_{\mathbf{r}}\right) \mathbf{k}_{\mathrm{w}}-\mathbf{k}_{\mathrm{m}} \Delta \mathbf{w}_{\mathbf{r}}\right) \Delta \Psi_{\mathrm{qr}}^{\mathrm{e}}$

$k_{w} \frac{d \Delta \Psi_{q r}^{e}}{d t}=\left(k_{w} \Delta w_{r}-2\left(w_{e}-w_{r}\right)\right) \Psi_{d r}^{e}-S_{r} k_{w} \Delta \Psi_{q r}^{e}+\left(k_{m} \Delta w_{r}-k_{w}\left(w_{e}-w_{r}\right)\right) \Delta \Psi_{d r}^{e}$ $+\mathbf{L}_{\mathbf{m}} \mathbf{S}_{\mathbf{r}}\left(2 \mathbf{i}_{\mathrm{qs}}^{\mathrm{e}}+\mathbf{k}_{\mathrm{w}} \Delta \mathbf{i}_{\mathrm{qs}}^{\mathrm{e}}\right)$

$\frac{\mathrm{d} \Delta \Psi_{\mathrm{dr}}^{\mathrm{e}}}{\mathrm{dt}}=\mathrm{L}_{\mathrm{m}} \mathrm{S}_{\mathbf{r}} \Delta \mathrm{i}_{\mathrm{ds}}^{\mathrm{e}}-\mathrm{S}_{\mathbf{r}} \Delta \Psi_{\mathrm{dr}}^{\mathrm{e}}+\left(\mathrm{w}_{\mathrm{e}}-\mathrm{w}_{\mathbf{r}}-\mathbf{k}_{\mathrm{w}} \Delta \mathbf{w}_{\mathbf{r}}\right) \Delta \Psi_{\mathrm{qr}}^{\mathrm{e}}$

$\frac{\mathrm{d} \Delta \Psi_{\mathrm{qr}}^{\mathrm{e}}}{\mathrm{dt}}=\mathrm{L}_{\mathrm{m}} \mathrm{S}_{\mathbf{r}} \Delta \mathrm{i}_{\mathrm{q} s}^{\mathrm{e}}-\mathrm{S}_{\mathbf{r}} \Delta \Psi_{\mathrm{qr}}^{\mathrm{e}}+\Delta \mathrm{w}_{\mathrm{r}} \Delta \Psi_{\mathrm{dr}}^{\mathrm{e}}-\mathbf{k}_{\mathrm{w}}\left(\mathrm{w}_{\mathrm{e}}-\mathbf{w}_{\mathbf{r}}-\mathbf{k}_{\mathrm{w}} \Delta \mathbf{w}_{\mathrm{r}}\right) \Delta \Psi_{\mathrm{dr}}^{\mathrm{e}}$

Thus the stator current expression in d-axis attained as follows

$i_{d s}^{e * s}=\frac{\Psi_{d \mathbf{r}}^{e}}{\mathbf{L}_{\mathrm{m}}^{\mathrm{e}}}+\frac{\left(\mathbf{k}_{\left.\mathrm{u} \Delta \mathrm{w}_{\mathrm{r}}-\mathbf{k}_{\mathrm{w}}{ }^{2}\right) \Delta \mathrm{w}_{\mathrm{r}} \Delta \psi_{\mathrm{q}}^{\mathrm{e}}}^{2}\right.}{2 \mathbf{L}_{\mathrm{m}} \mathbf{S}_{\mathbf{r}}}$

\subsection{Calculation of Summation torque}

In order to find the weigh torque value, the torque of each motor must be determined and summed, they are represented as $\mathbf{T}_{\mathbf{1}}$ and $\mathbf{T}_{2}$. The summation torque of the dual induction motor is given by $\mathbf{T}_{\mathbf{s}}$.

$\mathrm{T}_{\mathrm{s}}=\mathrm{T}_{1}+\mathrm{T}_{2}$

$\mathrm{T}_{1}=\psi_{\mathrm{r} 1}^{\mathrm{e}} * \mathrm{i}_{\mathrm{s} 1}^{\mathrm{e}}$

$\mathrm{T}_{2}=\psi_{\mathrm{r} 2}^{\mathrm{e}} * \mathrm{i}_{\mathrm{s} 2}^{\mathrm{e}}$

$\mathrm{T}_{\mathrm{s}}=\mathrm{T}_{1}+\mathrm{T}_{2}=\mathrm{k}_{\mathrm{x}}\left(\Psi_{\mathrm{r} 1}^{\mathrm{e}} * \mathrm{i}_{\mathrm{s} 1}^{\mathrm{e}}+\psi_{\mathrm{r} 2}^{\mathrm{e}} * \mathrm{i}_{\mathrm{s} 2}^{\mathrm{e}}\right)$

Where,

$k_{x}=1.5 n_{p} L_{m} / L_{r}$

Now expanding equation (10) by Substituting equation (1) and (2), The summation torque is given in equation (12)

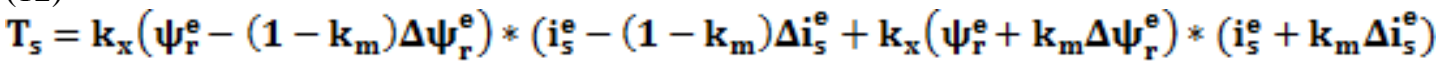

$$
\begin{aligned}
& \frac{\mathrm{T}_{\mathrm{s}}}{\mathbf{k}_{\mathrm{x}}}=2 \Psi_{\mathrm{dr}}^{\mathrm{e}} \mathbf{i}_{\mathrm{q} s}^{\mathrm{e}}+\mathbf{k}_{\mathrm{u}}\left(\Delta \Psi_{\mathrm{dr}}^{\mathrm{e}} \Delta \mathbf{i}_{\mathrm{q} s}^{\mathrm{e}}-\Delta \mathbf{i}_{\mathrm{ds}}^{\mathrm{e}} \Delta \Psi_{\mathrm{qr}}^{\mathrm{e}}\right)+\mathbf{k}_{\mathrm{w}}\left(\boldsymbol{\Psi}_{\mathrm{dr}}^{\mathrm{e}} \Delta \mathbf{i}_{\mathrm{q} s}^{\mathrm{e}}+\Delta \Psi_{\mathrm{dr}}^{\mathrm{e}} \Delta \mathbf{i}_{\mathrm{q} s}^{\mathrm{e}}-\mathbf{i}_{\mathrm{d} s}^{\mathrm{e}} \Delta \Psi_{\mathrm{qr}}^{\mathrm{e}}\right)
\end{aligned}
$$


The summing torque in the $\mathrm{d}-\mathrm{q}$ frame (equation 13) is obtained by substituting equation (4) in the equation (12).

\subsection{Calculation of reference current}

The reference stator current expression in q-axis is obtained as follows

$\mathbf{i}_{\mathrm{q} s}^{e s}=\frac{\frac{\mathrm{T}_{\mathrm{s}}}{\mathrm{k}_{\mathrm{x}}}-\mathbf{k}_{\mathrm{w}}\left(\Psi_{\mathrm{dr}}^{\mathrm{e}} \Delta \mathrm{i}_{\mathrm{q} s}^{\mathrm{e}}-\mathrm{i}_{\mathrm{ds}}^{\mathrm{e}} \Delta \Psi_{\mathrm{qr}}^{\mathrm{e}}\right)-\mathbf{k}_{\mathrm{u}}\left(\Delta \Psi_{\mathrm{dr}}^{\mathrm{e}} \Delta \mathbf{i}_{\mathrm{q} s}^{\mathrm{e}}-\Delta \mathrm{i}_{\mathrm{ds}}^{\mathrm{e}} \Delta \Psi_{\mathrm{qr}}^{\mathrm{e}}\right)}{2 \Psi_{\mathrm{dr}}^{\mathrm{e}}+\mathbf{k}_{\mathrm{w} \Delta \Psi_{\mathrm{dr}}^{\mathrm{e}}}^{\mathrm{e}}}$

\subsection{Weighed value calculations}

The weight value $\mathbf{k}_{\mathbf{m}}$ consists of two components say

1) Torque component $\mathrm{k}_{\mathrm{mt}}$

2) Speed component $k_{m s}$

The components are calculated by the practical torque and speed obtained which are illustrated as

$$
\mathbf{k}_{\mathrm{mt}}=\frac{\mathrm{T}_{1}}{\mathbf{T}_{1}+\mathbf{T}_{2}}
$$

$\mathbf{k}_{\mathrm{ms}}=\mathbf{k}_{\mathrm{ms}}+\operatorname{sign}\left(\mathbf{k}_{\mathrm{msd}}\right) \mathbf{d}_{\mathrm{p}} \cdot \mathbf{k}_{\mathrm{msd}} \geq \mathbf{d}_{\mathrm{x}}$

$\mathbf{k}_{\mathrm{ms}}=\mathbf{k}_{\mathrm{ms}}-\operatorname{sign}\left(\mathbf{k}_{\mathrm{msd}}\right) \mathbf{d}_{\mathbf{n}} \cdot \mathbf{k}_{\mathrm{msd}}<\mathbf{d}_{\mathrm{x}}$

\section{Simulations and Results}

4.1 Results using Fuzzy Controller

\subsubsection{Simulation of speed control of dual IM using fuzzy controller}

The figure 3 depicts the simulation of vector speed control of dual induction motor implementing fuzzy controller developed in the MATLAB.

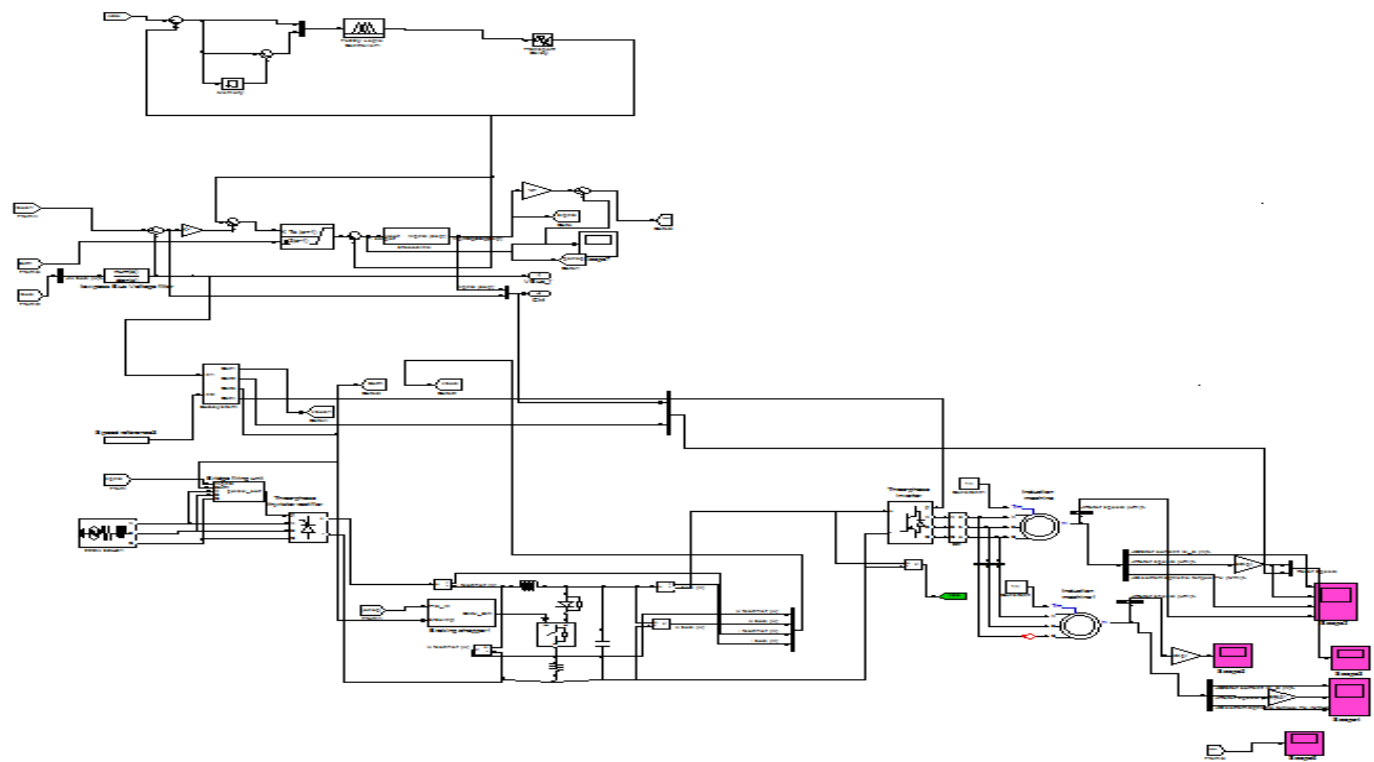

Fig 3: Simulation of Speed control of Dual Induction motor using fuzzy Controller 


\subsubsection{Output graph}

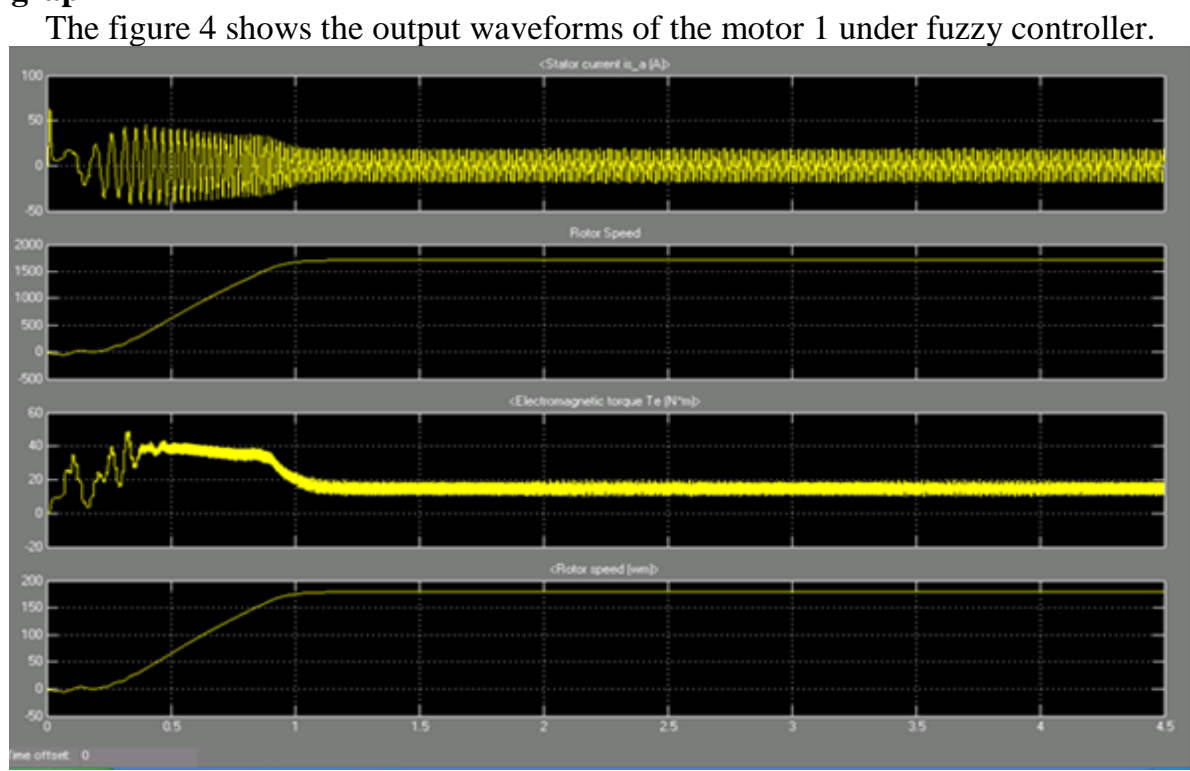

Fig 4: output graph obtained for motor 1

The figure 5 shows the output waveforms of the motor 2 under fuzzy controller.

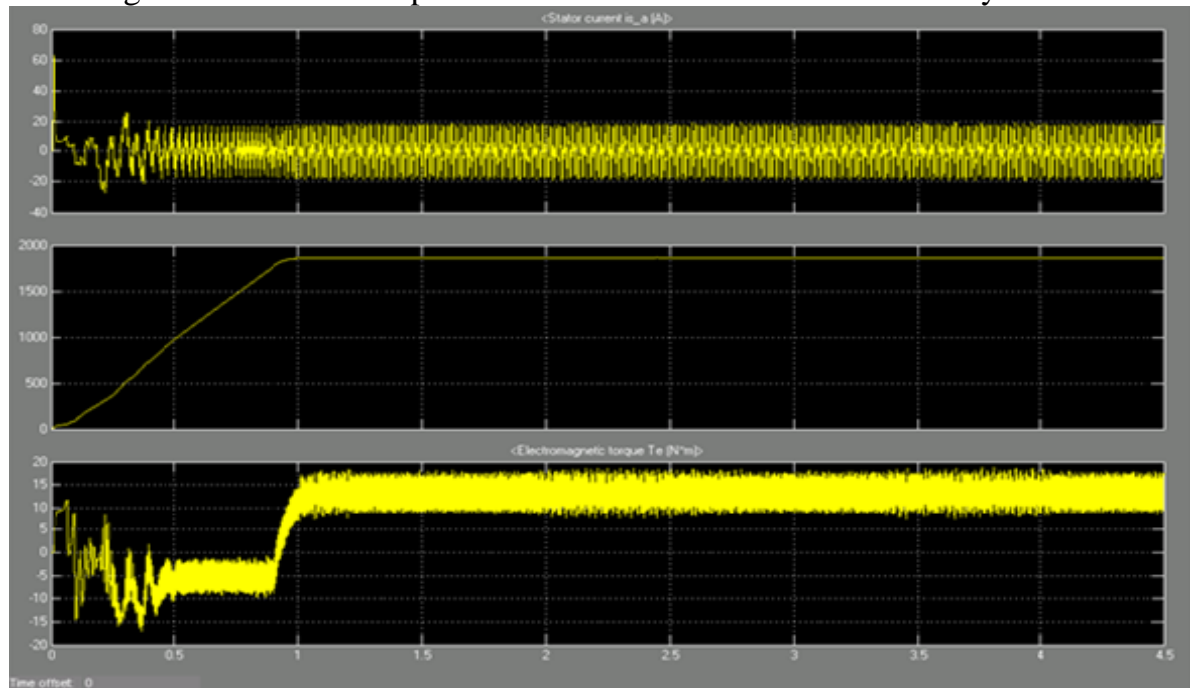

Fig 5: output graph obtained for motor 2

From the fig 4 and fig 5, it is clear that the starting torque is obtained well while using fuzzy controller and the harmonics is also considerably low.

\subsection{Inference}

The simulation graph results prove that under unbalanced load conditions the control of dual induction motor is achieved using fuzzy controllers by adjusting the weighted value. It is observed that the oscillations are considerably less and the steady state is reached within a short interval of time.

\section{Conclusion}

In this project work, the weighed vector speed control of dual induction motor using fuzzy logic controller under unbalanced load condition is demonstrated. A frame work is developed for obtaining the weighed vector value. Modeling of induction motor is also presented. A simulation is done in MATLAB to accomplish the weighed vector control of dual induction motor. The effectiveness of the system is analyzed through the graph achieved from the simulation. The results shows that the fuzzy logic controller is more effective than PI controller in controlling dual induction motor speed. As a future work, the hardware of the project can be implemented and more advanced controller can be used instead of fuzzy controllers 


\section{REFERENCES}

\section{Journal Papers:}

[1] Furuya A., Oka K., and Matsuse K. "A characteristic analysis of four-leg inverter in Two ac motor drives with independent vector control“- Proc. Int. Conf. Electr. Mach. Syst., 2007 pp. 619-624.

[2] Constantin Von Altrock "Fuzzy Logic and Neuro Fuzzy in Appliances “, -Fuzzy Application Library/Technical Applications/Fuzzy in Appliances presented in Embedded Systems Conferences, Santa Clara. 1996.

[3] Lee R. J., Pillay P. and Harley R. G. “d-q reference Frames for the Simulation of Induction Motors “- Electric Power Systems Research., 1984 pp. 15 -26.

[4] Fei XU, Liming Shi and Yaohua Li "The Weighted Vector Control of Speed Irrelevant Dual Induction Motors Fed by the Single Inverter “, - IEEE Transactions On Power Electronics, 2013 Vol. 28, No. 12.

[5] Kemal Ari, Faik Tekin Asal and Mert Coşgun "Project report on PI, PD, PID controllers “ - under Middle East Technical University.

[6] Jaroslav Lepka, Petr Stekl “Design of Motor Control Application” Freescale Semiconductor Application Note AN1930 2005 Rev. $2,2 / 2005$.

[7] Jaime Fonseca, Joao L. Afonso , Juilio S. Martin and Carlos Couto "Fuzzy logical speed control of an induction motor" department of Industrial Electronics, Minho University, Microprocessor and Micro controller, 1998 pp.523- 534.

[8] Matsumoto Y., Osawa C., Mizukami T., and Ozaki S., “A stator-flux-based vector control method for parallel-connected multiple induction motors fed by a single inverter "- in Proc. 13th Annu. Appl. Power Electron. Conf. Expo.,1998 Vol. 2, pp. 575-580.

[9] Matsumoto Y. and Kawamura A. "A novel vector control of single-inverter multiple-induction-motors drives for Shinkansen traction system“- in Proc. 16th Annu. Appl. Power Electron. Conf. Expo., 2001, Vol. 1, pp. 608-614.

[10] Matsuse K. K., Kouno H., and Oikawa J. "Characteristics of speed sensor less vector controlled dual induction motor drive connected in parallel fed by a single inverter “- IEEE Trans. Ind. Appl., Vol. 40, no. 1, 2004 pp. $153-161$. 